\title{
Biogeochemistry and carbon mass balance of a coccolithophore bloom in the northern Bay of Biscay (June 2006)
}

\author{
J. Harlay ${ }^{1,2}$, L. $\mathrm{CHOU}^{2}$, N. VAN Oostende ${ }^{3}$, K. $\mathrm{SABBE}^{3}$, A.V. Borges ${ }^{1}$ \\ ${ }^{1}$ AGO/Chemical Oceanography Unit, University of Liège, Belgium \\ 2 Océanographie chimique et Géochimie des Eaux, Université Libre de Bruxelles, Belgium \\ ${ }^{3}$ Protistology and Aquatic Ecology, Gent University, Belgium
}

Primary production (PP), calcification (CAL), bacterial production (BP) and dark community respiration (DCR) were measured along with a set of various biogeochemical variables, in early June 2006, at several stations at the shelf break of the northern Bay of Biscay. The cruise was carried out after the main spring diatom bloom that, based on the analysis of a time-series of remotely sensed chlorophyll-a (Chl-a), peaked in mid-April. Remotely sensed sea surface temperature (SST) indicated the occurrence of enhanced vertical mixing (due to internal tides) at the continental slope, while adjacent waters on the continental shelf were stratified, as confirmed by vertical profiles of temperature acquired during the cruise. The surface layer of the stratified water masses (on the continental shelf) was depleted of inorganic nutrients. Dissolved silicate (DSi) levels probably did not allow significant diatom development. We hypothesize that mixing at the continental slope allowed the injection of inorganic nutrients that triggered the blooming of mixed phytoplanktonic communities dominated by coccolithophores (Emiliania huxleyi) that were favoured with regards to diatoms due to the low DSi levels. Based on this conceptual frame, we used an indicator of vertical stratification to classify the different sampled stations, and to reconstruct the possible evolution of the bloom from the onset at the continental slope (triggered by vertical mixing) through its development as the water mass was advected on-shelf and stratified. We also established a carbon mass balance at each station by integrating in the photic layer PP, CAL and DCR. This allowed computation at each station of the contribution of PP, CAL and DCR to CO2 fluxes in the photic layer, and how they changed from one station to another along the sequence of bloom development (as traced by the stratification indicator). This also showed a shift from net autotrophy to net heterotrophy as the water mass aged (stratified), and suggested the importance of extracellular production of carbon to sustain the bacterial demand in the photic and aphotic layers. 